\title{
Monitoring eye movements during the learning of high and low meaningfulness paired-associate lists '
}

Eye movements were monitored as Ss learned a high (Group $H$ ) and a low (Group L) $m$ ' PA list. The learning for Group $H$ was superior while the fixation functions of the two groups did not differ reliably. These date, and others, were interpreted as being consistent with a two-stage conceptualization, with the first stage being relatively brief and with Group L Ss exhibiting some difficulty with it.

In each of three earlier investigations (McCormack \& Haltrecht, 1966; Haltrecht \& McCormack, 1966; McCormack, Haltrecht, \& Hannah, 1967) eye movements were monitored while Ss learned verbal paired-associates (PAs) by the recall method. In all cases, CVCs with meaningfulness ( $m^{\prime}$ ) values (Noble, 1961) within the range 1.80-1.93 were employed, and were chosen so as to assure low intralist stimulus and response similarity. During early learning trials, Ss viewed the response more than the stimulus while looking first to the stimulus and then to the response. As learning progressed, the stimulus came to be viewed more than the response, with Ss exhibiting a pattern of looking first to the stimulus, then to the response, then back to the stimulus. These findings were interpreted as being consistent with a two-stage conceptualization of verbal learning (Underwood \& Schulz, 1960), Ss presumably consolidating the responses during the initial or "response-learning" phase and then connecting them to the appropriate stimuli during the second or "hook-up" stage. Since eye monitoring techniques have been sensitive only to the transition from Stage 1 to Stage 2, and since there were several indications in one of these studies (Haltrecht \& McCormack, 1966) that response-consolidation is a relatively brief process, it is unlikely that eye movement photography will reflect any differences that might exist between groups of Ss or between different types of materials except at the extremities of these dimensions. The $m^{\prime}$ dimension was chosen as the independent variable in the present investigation, with one group of Ss learning a high $\mathrm{m}^{\prime}$ list and another a low $\mathrm{m}^{\prime}$ list. Subjects and Apparatus

Ss were 14 male and 16 female students of introductory psychology. Each list was made up of seven pairs of CVCs, one with $\mathrm{m}$ ' values within the range 1.23-1.55 and the other with $\mathrm{m}^{\prime}$ values ranging from 2.33-2.48. These lists were projected by means of a timer-controlled Carousel unit to a white-surfaced screen $1.4 \mathrm{~m}$ from $\mathrm{S}$ and $2.4 \mathrm{~m}$ from the projector. Eye movements were recorded by means of a head-mounted eye-marker camera (Mackworth \& Thomas, 1962), consisting of a 2 x $8 \mathrm{~mm}$ motion picture unit filming at a speed of 16 frames per sec and a periscope that reflects a spot of light from the cornea to the film. The film, when developed, shows the PA slides and, superimposed upon each, a bright circular spot indicating the approximate position of actual fixation. The data were analyzed frame by frame by examining the S-R slides through a filmviewer.

\section{Procedure}

Ss were assigned at random to two groups, Group $\mathrm{H}$ (high $\mathrm{m}^{\prime}$ ) and Group L (low $\mathrm{m}^{\prime}$ ), with the restriction that there be seven males and eight females in each. On any given trial, the seven S-R pairs were presented consecutively. During the study phase, $S$ was instructed to examine the pairs in an attempt to learn them. Following a 2-sec interval, the seven stimuli were presented, with $S$ attempting to recall the appropriate responses during this test phase. Slides changed every $2 \mathrm{sec}$, the intertrial interval was $2 \mathrm{sec}$, and a $1-\mathrm{min}$ rest was given at the end of every four trials to enable film changeover. The lists were presented in each of four different random orders in an attempt to minimize serial learning and the session was terminated at the completion of 16 trials. As in the previous investigations, the data were analyzed for the first eight trials only.

\section{Results and Discussion}

Since meaningfulness is one of the few variables that produces any marked effects on the rate of verbal learning (Underwood \& Schulz, 1960), it was not surprising to find that Group $\mathrm{H}$ learned at a faster rate than Group $\mathrm{L}$. During the first eight trials the former group elicited a total of 258 correct responses as opposed to 133 of the latter group. A Mann-Whitney U test demonstrated that this difference was highly dependable $(p<.01)$.

An analysis of variance of the fixation data, however, did not reveal any reliable differences between the fixation functions of the two groups; i.e., the F-ratio for the $H$ vs $L$ by $S$ vs $R$ by Trials interaction did not dependably exceed its expected value of unity. This analysis was supplemented by recording for each $S$ in each group that trial where the stimulus was first viewed more than the response. The mean trial for Group $H$ was 2.73, while that for Group $L$ was 3.20. These means were not, however, dependably different. The fixation data for the two groups were therefore pooled and are depicted in Fig. 1, where the first eight trials are shown along the abscissa and the ordinate represents mean number of 


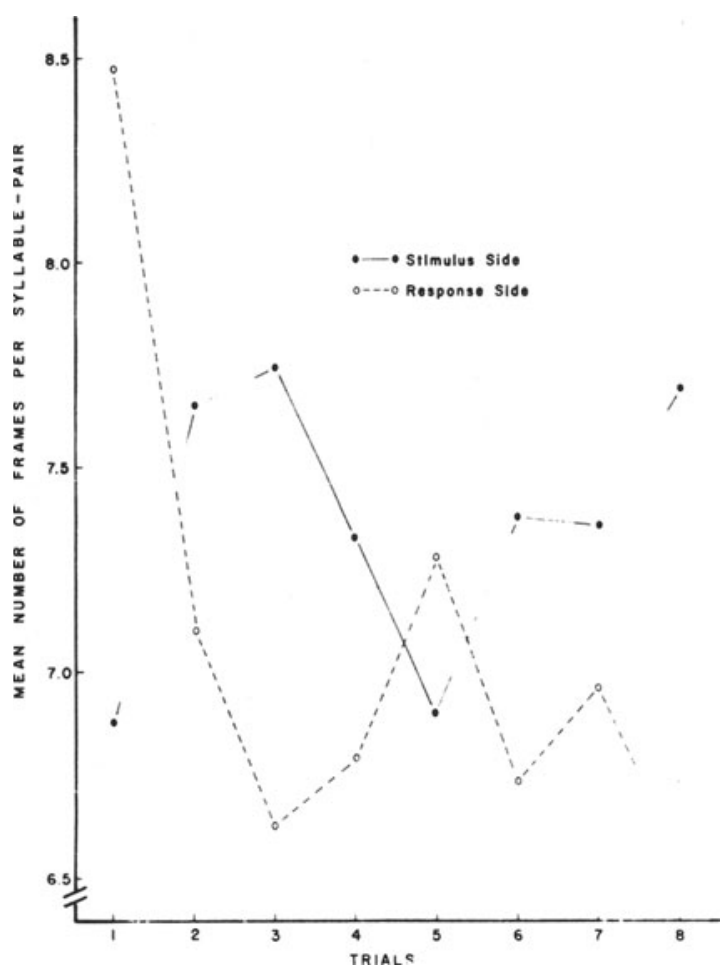

Fig. 1. Mean number of stimulus and response frames per syllable-pair as a function of the first eight trials pooled for both groups of Ss.

frames per syllable-pair for those slides where the stimulus and response appeared together. The solid line with closed circles represents stimulus frames while the response frames are represented by a broken function with open circles. The findings portrayed by Fig. 1 are consistent with earlier studies where time spent viewing the response decreased while stimulus viewingtime increased with trials, the F-ratio for the S vs $R$ by Trials interaction being reliably greater than unity ( $F$ $=3.66, \mathrm{df}=7 / 90, \mathrm{p}<.01$ ). The first crossover point, however, was temporally earlier than in previous studies.

The lack of any reliable differences between the fixation functions of the two groups was unexpected, but was consistent with previous indications that response-consolidation is a relatively brief process. The groups did differ, however, in terms of total fixation time, with the mean number of frames per S-R pair per trial for Group $\mathrm{L}$ being 7.46 while that for Group $\mathrm{H}$ was 6.96 ( $\mathrm{F}$ for Groups $=8.56, \mathrm{df}=1 / 26, \mathrm{p}<.01$ ). This could not be accounted for by less attending over trials on the part of Group $\mathrm{H}$, a phenomenon occasionally seen in previous experiments, since the Trials by Groups interaction was not statistically dependable. There were no reliable eye movement differences between the groups, with each showing a dependable Trials effect $(F=5.38, \mathrm{df}=7 / 18$, $\mathrm{p}<.001)$ reflecting a transition from $\mathrm{S}-\mathrm{R}$ to $\mathrm{S}-\mathrm{R}-\mathrm{S}$ viewing during the early trials.

One of the more interesting findings of the present study was the increased viewing of the response from
Trials 4-5 where a 1-min rest was introduced to enable $E$ to change film. This may be seen in Fig. 1. It should be noted that the overall increase at this point is entirely attributable to the Ss of Group L. This finding is consistent with those of earlier studies. It was observed as a detectable phenomenon in one study (McCormack, Haltrecht, \& Hannah, 1967), but failed to appear in another (McCormack \& Haltrecht, 1966). In both investigations a cross-section of Ss had been exposed to middle $m$ ' materials. It was quite prominent in an investigation where "slow" learners studied middle $\mathrm{m}$ ' materials, but was absent with "fast" learners (Haltrecht \& McCormack, 1966). This phenomenon, therefore, has been observed whenever the material has been difficult, whether this be due to the nature of the list, as in the present study, or to the nature of the $S$, or both. It may be that Underwood's (Underwood, 1961) now abandoned statement (Underwood \& Ekstrand, 1967) that "when DP facilitates verbal learning the evidence points strongly toward the fact that it does so because of interference operating during the response learning stage" may in fact be correct. If the 1-min rest may be considered as establishing a condition analogous to that usually found in distributed practice, and if it may be assumed that some response-consolidation is still taking place for Ss of Group $L$ in the learning task involved here, then the data are consistent with Underwood's original statement. It is not argued that the fixation data give direct evidence of interference in the response learning stage, but the regression in terms of response viewing on the part of Group L Ss seems to indicate the presence of response interference which might be expected when consolidation is incomplete.

\section{References}

Haltrecht, E. J., \& McCormack, P. D. Monitoring eye movements of slow and fast learners. Psychon. Sci., 1966, 6, 461-462.

Mackworth, N. H., \& Thomas, E. L. Head-mounted eye-marker camera. J. Opt. Soc. Amer., 1962, 52, 713-716.

McCormack, P. D., \& Haltrecht, E. J. Monitoring eye movements under two conditions of presentation of paired-associate materials. Canad. J. Psychol., 1966, 20, 154-159.

McCormack, P. D., Haltrecht, E. J., \& Hannah, T. E. Supplementary Report: Monitoring eye movements during the learning of successive paired-associate lists. J. verbal Learn. verbal Behav., 1967, in press.

Noble, C. E. Measurement of associative value (a), rated associations (a') and scaled meaningfulness (m') for the $2100 \mathrm{CVC}$ com binations of the English alphabet. Psychol. Rep., 1961, 8, 487521.

Underwood, B. J. Ten years of massed practice on distributed practice. Psychol. Rev., 1961, 68, 229-247.

Underwood, B. J., \& Ekstrand, B. R. Effect of distributed practice on paired-associate learning. J. exp. Psychol. Monogr. Suppl., 1967, 73, (Whole No. 634).

Underwood, B. J., \& Schulz, R. W. Meaningfulness and verbal learning. Chicago: Lippincott, 1960.

\section{Note}

1. This research was supported by a grant-in-aid from the Associare Committee on Experimental Psychology of the National Research Council of Canada (Grant APA-78). The authors are indebted to W. J. Bradley, T. E. Moore and P. Rhoades for data collection. 